\title{
Randomised Controlled Trial of a Pediatric Tracheostomy Care Education Program for Homecare Nurses
}

\author{
Jenny Shi ${ }^{1}$, Julia Orkin ${ }^{1}$, Catharine $\mathrm{Walsh}^{2}$, Stephanie $\mathrm{Chu}^{1}$, Krista Keilty ${ }^{3}$, Sandra \\ Mckay $^{1}$, Cora Mocanu ${ }^{4}$, Adam Qazi ${ }^{1}$, Munazzah Ambreen $^{5}$, and Reshma Amin ${ }^{2}$ \\ ${ }^{1}$ The Hospital for Sick Children \\ ${ }^{2}$ Hospital for Sick Children Research Institute \\ ${ }^{3}$ Hospital for Sick Children \\ ${ }^{4}$ York University \\ ${ }^{5}$ The Hospital for Sick Children Department of Paediatrics
}

October 29, 2021

\begin{abstract}
Objective: To evaluate the immediate and sustained knowledge retention and sense of self-efficacy of homecare nurses following completion of a standardized competency-based tracheostomy education course. Safe discharge of children requiring tracheostomy with or without ventilation relies on the competence of homecare nurses. Study Design: Pragmatic, randomized controlled trial of 44 homecare nurses. Participants were randomized into the intervention group $(\mathrm{n}=21)$, which received the tracheostomy course, or the control group $(\mathrm{n}=23)$, which received an enterostomy and vascular access course. Multiple-choice question (MCQ) knowledge assessments and self-efficacy questionnaires were administered to both groups pre-course and postcourse at 6 week, 3 month, 6 month, and 12 month follow-ups. Results: Twenty participants in the intervention group and 19 in the control group were included. Four withdrew from the study and two crossed over from the control into the intervention arm. The change in mean self-efficacy scores (total score $=100$ ) was significantly higher in the intervention group than in the control group at 6 weeks (intervention (mean $\pm \mathrm{SD}$ ): $18.6 \pm 14.5$; control: $6.6 \pm 20.4 ; \mathrm{p}=0.04$ ) and 3 months (intervention: 19.6 \pm 14.2 ; control: $5.2 \pm 17.0 ; \mathrm{p}=0.007$ ), and trended higher at 6 months (intervention: $18.0 \pm 14.5 ;$ control: $6.9 \pm 24.1 ; \mathrm{p}=0.1$ ) and 12 months (intervention: 16.9 \pm 15.0 ; control: $16.8 \pm 20.5 ; \mathrm{p}=1.0$ ). The change in mean MCQ assessment scores (total score $=20)$ trended higher in the intervention group than in the control group at 6 weeks (intervention (mean $\pm \mathrm{SD}$ ): 1.8 \pm 2.2 ; control: 1.6 , $\pm 2.9 ; \mathrm{p}=0.8$ ). Conclusions: Homecare nurses who attended the tracheostomy course demonstrated a higher sense of self-efficacy at long-term follow-up.
\end{abstract}

\section{Hosted file}

Tracheostomy Manuscript Pediatric Pulmonology.docx available at https://authorea.com/users/ 443653/articles/543617-randomised-controlled-trial-of-a-pediatric-tracheostomy-careeducation-program-for-homecare-nurses

\section{Hosted file}

Trach Figures and Tables - Peds Pulm.docx available at https://authorea.com/users/443653/ articles/543617-randomised-controlled-trial-of-a-pediatric-tracheostomy-care-educationprogram-for-homecare-nurses 